\title{
Dual-mode cultivation of Chlorella protothecoides applying inter-reactors gas transfer improves microalgae biodiesel production
}

\author{
C.A. Santos ${ }^{\mathrm{a}}$, B. Nobre ${ }^{\mathrm{a}}$, T. Lopes da Silva ${ }^{\mathrm{a}}$, H.M. Pinheiro ${ }^{\mathrm{b}}$, A. Reis ${ }^{\mathrm{a}, *}$ \\ a LNEG I.P., U. Bioenergia, ed. F, Estrada do Paço do Lumiar, 22, 1649-038 Lisbon, Portugal \\ ${ }^{\mathrm{b}}$ Centre for Biological and Chemical Engineering, IBB - Institute for Biotechnology and Bioengineering, Department of Bioengineering, Instituto Superior \\ Técnico, University of Lisbon, Av. Rovisco Pais, 1049-001 Lisbon, Portugal
}

\section{A R T I C L E I N F O}

\section{Article history:}

Received 6 February 2014

Received in revised form 2 May 2014

Accepted 12 May 2014

Available online 23 May 2014

\section{Keywords:}

Chlorella protothecoides

Heterotrophic

Autotrophic

Biodiesel

Carbon dioxide fixation

\begin{abstract}
A B S T R A C T
Chlorella protothecoides, a lipid-producing microalga, was grown heterotrophically and autotrophically in separate reactors, the off-gases exiting the former being used to aerate the latter.

Autotrophic biomass productivity with the two-reactor association, $0.0249 \mathrm{~g} \mathrm{~L}^{-1} \mathrm{~h}^{-1}$, was 2.2 -fold the value obtained in a control autotrophic culture, aerated with ambient air. Fatty acid productivity was 1.7 -fold the control value.

C. protothecoides heterotrophic biomass productivity was $0.229 \mathrm{~g} \mathrm{~L}^{-1} \mathrm{~h}^{-1}$. This biomass' fatty acid content was $34.5 \%(\mathrm{w} / \mathrm{w}$ ) with a profile suitable for biodiesel production, according to European Standards.

The carbon dioxide fixed by the autotrophic biomass was $45 \mathrm{mg} \mathrm{CO}_{2} \mathrm{~L}^{-1} \mathrm{~h}^{-1}$ in the symbiotic arrangement, 2.1 times the control reactor value.

The avoided $\mathrm{CO}_{2}$ atmospheric emission represented $30 \%$ of the $\mathrm{CO}_{2}$ produced in the heterotrophic stage, while the released $\mathrm{O}_{2}$ represented $49 \%$ of the oxygen demand in that stage.

Thus, an increased efficiency in the glucose carbon source use and a higher environmental sustainability were achieved in microalgal biodiesel production using the proposed assembly.
\end{abstract}

(c) 2014 Elsevier B.V. All rights reserved.

\section{Introduction}

Microalgae are a promising, alternative source of oil for biodiesel production, showing many advantages over the present sources, mainly higher plants. The main advantages offered by microalgae are higher photosynthetic efficiency and biomass productivity when compared to plants. Additionally, microalgae cultures can use non-arable land and non-potable water, do not compete with food, and their production is not seasonal, allowing daily harvesting. The oil yield from algae is estimated to be 9-fold higher than the highest oil yield in plants, reported for palm (Chisti, 2007).

However, microalgal biomass production is, at present, still more expensive than growing plants. The key factors affecting profitability in this industry are capital costs, directly affected by biomass productivity, together with the market price of the products, presently only high-value products (Stephens et al., 2010).

Therefore, further research is necessary before economic viability of biodiesel production from algae can be attained.

To improve microalgae productivity, the use of fully controlled closed bioreactors is a necessary tool. When compared to open

\footnotetext{
* Corresponding author. Tel.: +351 210924726; fax: +351 217163636

E-mail address: alberto.reis@lneg.pt (A. Reis).
}

reactors, closed photobioreactors generally provide higher biomass concentrations, higher growth rates and reduced risk of microbial contamination (Tredici, 2004). Moreover, heterotrophic growth in fermenters can reduce the production cost of microalgal biomass by a factor of ten (Lee, 2004). The microalga Chlorella protothecoides is an excellent candidate for biodiesel production, since it can achieve high biomass productivity and high lipid content values, with a suitable fatty acid profile for biodiesel production, when grown under selected conditions. Furthermore, it is able to grow both photoautotrophically and heterotrophically, thus offering the alternative of photobioreactors and fermenters for its growth.

Several studies have been reported using C. protothecoides for a variety of purposes. In earlier studies the $C$. protothecoides strain CS-41 from the CSIR Marine Laboratory, Australia (Shi et al., 1999), was heterotrophically cultured in glucose-limited batch fermentation $(3.7 \mathrm{~L})$, at $28^{\circ} \mathrm{C}, \mathrm{pH} 6.6$, agitation speed $480 \mathrm{rpm}$ and dissolved oxygen above $50 \%$ of saturation, to produce lutein-rich biomass. Using an initial glucose concentration of $40 \mathrm{~g} \mathrm{~L}^{-1}$ the culture attained a maximum biomass concentration of $18.4 \mathrm{~g} \mathrm{~L}^{-1}$ after $178 \mathrm{~h}$, with a productivity of $0.103 \mathrm{~g} \mathrm{~L}^{-1} \mathrm{~h}^{-1}$; after glucose depletion, this Chlorella strain went on to attain a maximum lutein content of $4.4 \mathrm{mg} \mathrm{g}^{-1}$ biomass dry weight. The specific growth rate of this strain was $0.0417 \mathrm{~h}^{-1}$ and the yields on consumed 